Article

\title{
Combined AOPs for Formaldehyde Degradation Using Heterogeneous Nanostructured Catalysts
}

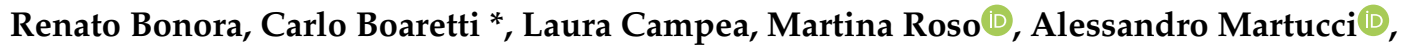 \\ Michele Modesti (D) and Alessandra Lorenzetti * \\ Department of Industrial Engineering, University of Padova, Via Marzolo 9, 35131 Padova, Italy; \\ renato.bonora@unipd.it (R.B.); lcampea94@gmail.com (L.C.); martina.roso@unipd.it (M.R.); \\ alex.martucci@unipd.it (A.M.); michele.modesti@unipd.it (M.M.) \\ * Correspondence: carlo.boaretti@unipd.it (C.B.); alessandra.lorenzetti@unipd.it (A.L.)
}

Received: 4 December 2019; Accepted: 9 January 2020; Published: 14 January 2020

check for updates

\begin{abstract}
In this paper we studied the combination of advanced oxidation processes (AOPs), i.e., $\mathrm{TiO}_{2}$-based photocatalysis and photo-Fenton process, on the degradation of aqueous solutions containing a low $(90 \mathrm{ppm})$ concentration of formaldehyde. Heterogeneous nanostructured catalysts, supported on polymeric nanofibers, were used; for comparison, some homogeneous or partly heterogeneous systems were also analyzed. Furthermore, to make the process more sustainable (in terms of costs and safety) no hydrogen peroxide was added to the system. The results showed that the combination of AOPs gave a synergy since the presence of iron was beneficial in promoting the photocatalytic activity of $\mathrm{TiO}_{2}$ while $\mathrm{TiO}_{2}$ was beneficial in promoting the photo-Fenton reaction. Moreover, very good results were obtained using fully heterogeneous nanostructured catalysts (based on $\mathrm{TiO}_{2}$ and $\mathrm{FeSO}_{4}$ ), without the need to add $\mathrm{H}_{2} \mathrm{O}_{2}$.
\end{abstract}

Keywords: formaldehyde; titanium dioxide; photocatalysis; photo-Fenton; heterogeneous catalyst; combination; synergy; AOPs; nanofibers

\section{Introduction}

Terrorism is a threat that, in recent decades, has become increasingly fearsome and destructive. It is known that chemical weapons and toxic compounds are used by terrorists in their attacks. For this reason, toxic industrial materials (TIMs), which are commonly used in the chemical industry, are the subject of discussion in many countries, where governments want to analyze and optimize the conditions of use and disposal of these hazardous chemicals. TIMs are characterized by high toxicity and wide availability [1]. This problem has led to the introduction of restrictive regulations on trade of these materials and on safety in chemical industries which, having a large quantity of toxic materials, are a sensitive target for possible terrorist actions and, therefore, require an adequate TIMs degradation system. To limit the spread of these substances, wastewater from industries, which could contain toxic compounds in high concentrations, should also be treated. One of the most dangerous TIMs is formaldehyde, a suspected carcinogenic chemical compound characterized by high toxicity, which is widely used in various sectors of the chemical industry (synthetic resins, insulators, paints, textiles) [2].

Advanced oxidation processes (AOPs) are considered the most effective treatments for the removal of these species from water [3], because they allow a complete mineralization even of the most refractory organic compounds, thus destroying wastewater pollutants and transforming them into less and even non-toxic products, thereby providing an ultimate solution for wastewater treatment.

Among the most widespread radical species used in AOPs, hydroxyl radical plays a primary role, since it is the most reactive oxidizing agent in water treatment (having a high oxidizing power [3]), it is very non-selective in its behavior and rapidly reacts with numerous species. Because hydroxyl radicals 
have a very short lifetime, they are only in situ produced during application through different methods, including a combination of oxidizing agents (e.g., $\mathrm{H}_{2} \mathrm{O}_{2}$ ), irradiation (such as ultraviolet (UV) light, or ultrasound), and catalysts (such as Fenton reagent, $\mathrm{Fe}^{2+}$, or titanium dioxide, $\mathrm{TiO}_{2}$ ) [4]. Indeed, hydroxyl radicals can be initiated by photons in the presence of catalysts (the most common being titanium dioxide, $\left.\mathrm{TiO}_{2}\right)$ or oxidants such as $\mathrm{H}_{2} \mathrm{O}_{2}\left(\mathrm{a} \mathrm{H}_{2} \mathrm{O}_{2}\right.$ molecule is cleaved by UV irradiation to generate two $\mathrm{OH} \bullet$ ); they are also produced in the presence of some metals (e.g., iron) which are able to activate $\mathrm{H}_{2} \mathrm{O}_{2}$. For example, in the so-called Fenton process, $\mathrm{H}_{2} \mathrm{O}_{2}$ reacts with $\mathrm{Fe}^{2+}$ to generate strong reactive species, like hydroxyl radicals, although other substances such as ferryl ions are proposed [5].

Several papers have already reported on the degradation of aqueous formaldehyde solution by photocatalytic process using titanium dioxide [6-9]. Some of them have used homogeneous catalysis, i.e., $\mathrm{TiO}_{2}$ particles suspended in contaminated water, which makes it necessary to recover them after treatment while the heterogeneous (i.e., supported) catalyst configurations, on the other hand, eliminate the need for catalyst filtration but generally result in a significant reduction in system efficiency [10].

Fenton and photo-Fenton processes have already been proposed for formaldehyde removal from wastewater [11-13]. In general, the Fenton and photo-Fenton processes require the use of ferrous ions $\left(\mathrm{Fe}^{2+}\right)$ and hydrogen peroxide $\left(\mathrm{H}_{2} \mathrm{O}_{2}\right)$ [14]. Thus, large amounts of $\mathrm{H}_{2} \mathrm{O}_{2}$ need to be irreversibly consumed in real application to treat wastewater containing a high concentration of organic pollutants, and considerable iron dosage is indispensable if higher efficiency is required $[15,16]$. In the Fenton process, there is a need for continuous addition of ferrous ion into the reaction medium for the reaction to proceed further. This disadvantage could be overcome by the use of photo-Fenton reagent, which is a cyclic process and regenerates $\mathrm{Fe}^{2+}$ ion [15], thus limiting the deposition of ferric ion sludge.

Based on the similarity between the mechanism of destruction in the case of different advanced oxidation processes (AOPs) [17], some research efforts focusing on the synergism between several AOPs have already been published. Mokhbi et al. [18] studied the effectiveness of photocatalysis with Fenton's reagent for treating oily wastewater; Kim et al. [19] studied the combined photocatalytic- and photo-Fenton system for treating some organic substrates (i.e., phenol, benzoic acid, and methanol); $\mathrm{Xu}$ et al. [15] studied interactions between $\mathrm{TiO}_{2}$ and $\mathrm{Fe}^{3+} / \mathrm{H}_{2} \mathrm{O}_{2}$ to degrade bisphenol A. They all used unsupported catalysts, i.e., $\mathrm{TiO}_{2}$ and $\mathrm{Fe}^{2+}$ were put in solution, in the presence of $\mathrm{H}_{2} \mathrm{O}_{2}$ and acidic $\mathrm{pH}$, and found that synergistic effects resulted. In other works, the combination of $\mathrm{TiO}_{2}$ and $\mathrm{Fe}$ ions has been proposed but without exploiting Fenton or photo-Fenton reactions; the main aim of those works was, indeed, to dope titania in order to modify its photocatalytic features, such as visible light absorption and photocatalytic efficiency. For example, Khanmohammadi et al. [20] studied the use of unsupported catalyst, composed of sol-gel synthesized $\mathrm{Fe}_{2} \mathrm{O}_{3}-\mathrm{TiO}_{2}$ nano hybrid, in the degradation of liquid-phase formaldehyde in the presence of ultraviolet and visible irradiation. They found that the degradation took place according to a two-step mechanism: first, formaldehyde was converted to formic acid and then this was converted to $\mathrm{H}_{2} \mathrm{O}$ and $\mathrm{CO}_{2}$ during a photocatalytic reaction via radical mechanism in the presence of UV irradiation. In a similar way, Siddhapara et al. [21] used sol-gel $\mathrm{TiO}_{2}$ nanoparticles doped with a transition metal $(\mathrm{Mn}, \mathrm{Fe}, \mathrm{Co})$ to degrade liquid formaldehyde solution; they found that the substitution with transition metals enhanced photocatalytic efficiency since transition metals increased defect sites and acted as a permanent space charge region, whose electric force improved the separating efficiency of electron-holes. Li et al. [22] studied the effect of the content of $\mathrm{Fe}$ on the photocatalytic performance of doped $\mathrm{TiO}_{2}$ on the degradation of gaseous formaldehyde and found that doped $\mathrm{TiO}_{2}$ exhibited higher photocatalytic activity under visible light irradiation. Cheng et al. [23] mixed $\mathrm{TiO}_{2}$ with iron oxide to produce modified photocatalysts $\left(\mathrm{Fe} / \mathrm{TiO}_{2}\right)$ and then coated them on a supporting medium of fiberglass and studied the degradation of gaseous formaldehyde using these supported catalysts. They concluded that the enhancement of formaldehyde decomposition by iron-doped $\mathrm{TiO}_{2}$ may be attributed to the facts that the doped iron ions could effectively enhance the absorption of UV-visible wavelength, increase the photocatalytic reactivity and retard the recombination of electron and electron-hole pairs, which thus contributed to the increase of formaldehyde decomposition efficiency. Chun et al. [24] studied the photocatalytic degradation of 
gaseous pollutants (benzene, toluene, ethyl benzene, and o-xylene (BTEX)) by preparing the $\mathrm{Fe}-\mathrm{TiO}_{2}$ catalyst by the sol-gel technique and electrospinning it in presence of polyvinyl pyrrolidone; they found enhanced photocatalytic activity in presence of optimal $\mathrm{Fe}: \mathrm{TiO}_{2}$ ratio.

However, authors using Fe-doped titania [20-24] did not mention the photo-Fenton reaction and did not adjust $\mathrm{pH}$ accordingly.

Nevertheless, in literature there are already some examples of combination of photocatalysis and photo-Fenton using supported catalysts. For example, Bouras et al. [25] combined a titania-supported photocatalyst as well as Photo-Fenton oxidation, by using $\mathrm{FeCl}_{2} \cdot 4 \mathrm{H}_{2} \mathrm{O}$ in solution, for the decolorization of aqueous solution of the azo dye Basic Blue 41. Only very few examples using a fully supported catalytic system based on $\mathrm{TiO}_{2}$ and $\mathrm{Fe}$ ions and exploiting photo-Fenton reaction can be found. For example, Quici et al., degraded oxalic acid [26], while Shao et al. [27] used $\mathrm{TiO}_{2}$ and $\mathrm{Fe}(\mathrm{III})$ meso-tetraphenylporphyrin on polystyrene nanofibers to degrade methyl orange under visible light. They electrospun solutions simultaneously containing polystyrene, porphyrin and $\mathrm{TiO}_{2}$ and found that this system, in presence of added $\mathrm{H}_{2} \mathrm{O}_{2}$, coupling photocatalysis and Fenton reaction gave the best performance. Zhang et al. [28] used $\mathrm{TiO}_{2} / \mathrm{Cu}_{2} \mathrm{O}$ composite coated on glass matrix to degrade methylene blue using both photocatalysis and the Fenton process, using in situ generated $\mathrm{H}_{2} \mathrm{O}_{2}$. In the paper of $\mathrm{Zhu}$ et al. [29], beta-iron oxyhydroxide ( $\beta-\mathrm{FeOOH})$ nanostructures on electrospun $\mathrm{TiO}_{2}$ nanofibers were synthesized and used to degrade methyl orange. They showed that the degradation was faster in the presence of added $\mathrm{H}_{2} \mathrm{O}_{2}$ but it still took place also without adding it.

In this paper we study the combination of $\mathrm{TiO}_{2}$-based photocatalysis and photo-Fenton process on the degradation of aqueous solutions containing a low $(90 \mathrm{ppm})$ concentration of formaldehyde to understand if synergy can be revealed. Heterogeneous nanostructured catalysts, supported on polymeric nanofibers, have been used; for comparison, some homogeneous or partly heterogeneous systems have also been analyzed. Furthermore, to make the process more sustainable (in terms of costs and safety) no hydrogen peroxide has been added to the system. To the best of our knowledge, this combination of advanced oxidation processes has never been studied in the literature for formaldehyde degradation.

\section{Materials and Methods}

\subsection{Materials}

Polyacrylonitrile (PAN, Mw = 150,000 g/mol, Sigma Aldrich, St. Louis, MO, USA) was used as support for the catalytic systems in electrospun form; $N, N$-dimethylformamide (DMF, Sigma-Aldrich, St. Louis, MO, USA) was used as electrospinning solvent. Ferrous sulfate $\left(\mathrm{FeSO}_{4} \cdot 7 \mathrm{H}_{2} \mathrm{O}\right)$ was used as a catalyst for the photo-Fenton process and was supplied by Sigma-Aldrich (St. Louis, MO, USA). A crystalline, titanium dioxide powder was used for photocatalytic process, i.e., Aeroxide ${ }^{\circledR} \mathrm{TiO}_{2}$ P90 $\left(\mathrm{d}=14 \mathrm{~nm}, \mathrm{BET}=90 \mathrm{~m}^{2} / \mathrm{g}, 90 / 10\right.$ anatase/rutile, crystal size $=11 \mathrm{~nm}$ [30] $)$, supplied by Evonik (Essen, Germany). We decided to use this one (instead of the most commonly used P25) because some preliminary trials (unpublished results) have shown that P90 was more active than P25 in our degradation systems. Some other authors reported similar results for different pollutants when using supported $\mathrm{TiO}_{2}$-based catalysts [30,31].

The aqueous formaldehyde solution for testing the catalytic activity was prepared by diluting formalin ( $37 \% \mathrm{w} / \mathrm{w}$ of formaldehyde and 10\% w/w of methanol), supplied by Scharlau (Barcelona, Spain), with distilled water to reach a final formaldehyde concentration of $90 \mathrm{ppm}$. When the photo-Fenton process was considered, it was necessary to use $0.2 \mathrm{~N}$ sulfuric acid $\left(\mathrm{H}_{2} \mathrm{SO}_{4}\right.$ at $98 \% \mathrm{w} / \mathrm{w}$, Sigma Aldrich, St. Louis, MO, USA) to set the $\mathrm{pH}$ around 3, because this type of process is favored by acid $\mathrm{pH}$ [12]. Hydrogen peroxide was used as was a 30\% (w/w) solution, supplied by Sigma Aldrich (St. Louis, MO, USA).

Finally, pentafluorobenzylhydroxylamine hydrochlorinated (PFBHA-HCl), purchased by Alfa Aesar (Haverhill, MA, USA), and 1,2-dibromopropane 98\% w/w as internal standard (Sigma-Aldrich, 
St. Louis, MO, USA) dissolved into hexane (Sigma-Aldrich, St. Louis, MO, USA) have been used for the derivatization and extraction process, needed to quantify formaldehyde content in aqueous solutions by gas chromatography-mass spectrometry (GC-MS), according to the U.S. Environmental Protection Agency (EPA) method 556.

\subsection{Preparation of the Nanostructured Catalytic Systems}

Supported nanostructured catalysts have been used. The support was made by electrospun PAN nanofibers, while electrospraying was used for the catalysts' deposition. In this way, the catalysts were completely placed on the upper surface of the membrane and so they were homogeneously irradiated by ultraviolet (UV) rays [32]. A schematic procedure is depicted in Figure 1. The use of nanofibers membranes as support allowed to have a very large surface area where the catalysts can be deposited.

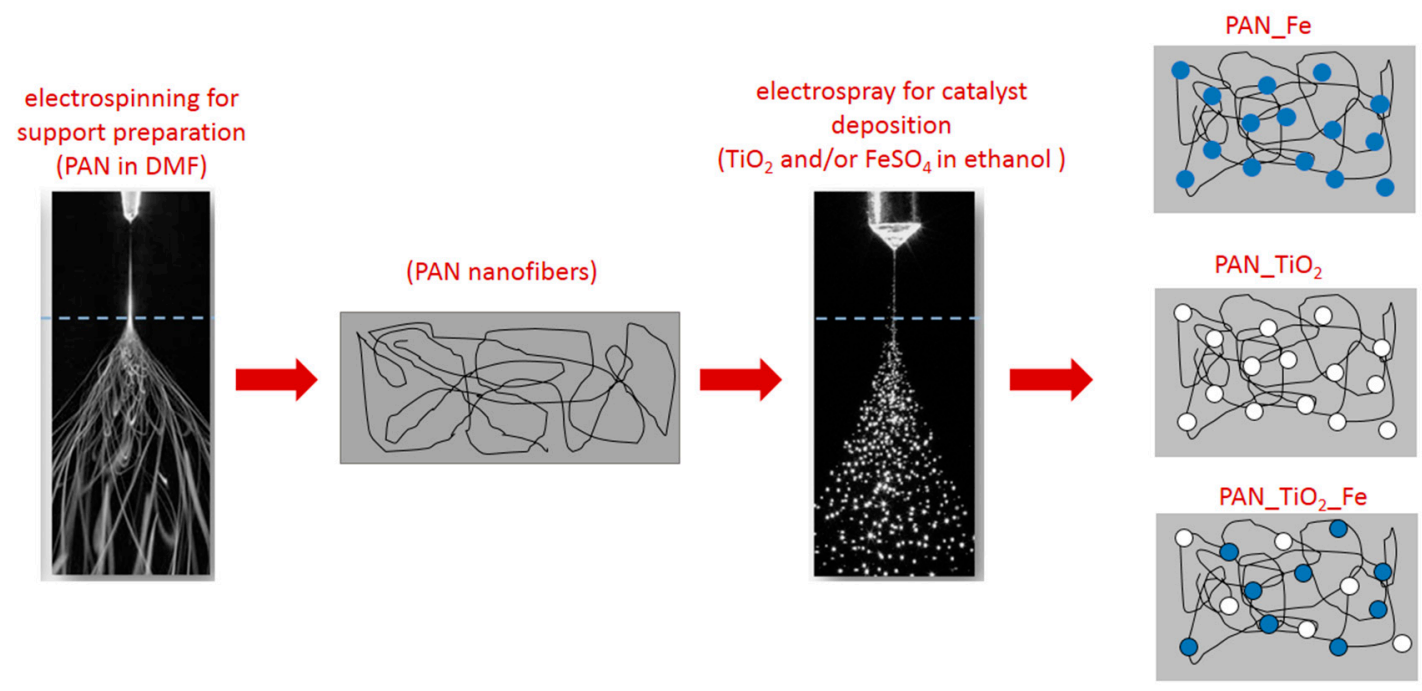

Figure 1. Schematic procedure for the preparation of nanostructured catalytic systems.

The first step in preparation was the production of PAN nanofiber membranes by electrospinning, using a solution of PAN in DMF at 5\% w/w, which must be stirred for not less than $15 \mathrm{~h}$. The homogeneous mixture was then transferred into a $5 \mathrm{~mL}$ syringe fitted with a $27 \mathrm{G}$ gauge needle. The syringe was put horizontally on a pump (NE-300 single syringe pump, NewEra Pump System Inc., Farmingdale, NY, USA) and the positive electrode of the high voltage power supply (Gamma High Voltage Inc., Ormond Beach, FL, USA), capable of generating voltages up to $60 \mathrm{kV}$, was clamped to the metal needle tip. The nanofibers were deposited on a metallic rotating collector. The process parameters are reported in Table 1.

Table 1. Process parameters for the membranes production.

\begin{tabular}{cccccc}
\hline Materials & $\begin{array}{c}\text { Flow Rate } \\
(\mathbf{m L} / \mathbf{h})\end{array}$ & $\begin{array}{c}\text { Voltage } \\
\mathbf{( k V )}\end{array}$ & $\begin{array}{c}\text { Electrode } \\
\text { Distance } \mathbf{( c m )}\end{array}$ & $\begin{array}{c}\text { Relative } \\
\text { Humidity } \mathbf{( \% )}\end{array}$ & $\begin{array}{c}\text { Deposition } \\
\text { Time (min) }\end{array}$ \\
\hline $\begin{array}{c}\text { PAN support } \\
\text { Catalysts deposition }\end{array}$ & 2 & $15 \div 20$ & $20 \div 25$ & $30 \div 40$ & 120 \\
\hline
\end{tabular}

For the catalysts deposition by electrospraying process, the catalysts were suspended into ethanol. $\mathrm{TiO}_{2}$ was used at $5 \% \mathrm{w} / \mathrm{w}$; this concentration was chosen in order to obtain a catalyst content of about $0.14 \mathrm{mg} / \mathrm{cm}^{2}$, which was, based on our previous experience [32], the optimal one to have a widespread distribution of titanium dioxide, avoiding great clusters, agglomeration and clogging of the nanostructured substrate. Moreover, at higher concentrations, an increase in opacity and light scattering of $\mathrm{TiO}_{2}$ particles occurs, leading to a decreased passage of irradiation through the sample [10]. 
For ferrous sulfate, based on mass balance calculation, a $4 \% \mathrm{w} / \mathrm{w}$ solution in ethanol should be enough to have the same catalyst content of titania and similar to that used in literature for a homogenous photo-Fenton system [11]. However, due to a partial loss of $\mathrm{FeSO}_{4}$ experienced during the electrospray process, owing probably to an interaction of the $\mathrm{Fe}^{2+}$ with the electric field, a $10 \% \mathrm{w} / \mathrm{w} \mathrm{FeSO}_{4}$ solution in ethanol has to be used. When the two catalysts were employed together, $\mathrm{TiO}_{2}$ was used at $5 \% \mathrm{w} / \mathrm{w}$ and the $\mathrm{FeSO}_{4}$ at $10 \% \mathrm{w} / \mathrm{w}$ dispersion in ethanol, in order to deposit a $50: 50 \mathrm{TiO}_{2}: \mathrm{FeSO}_{4}$ catalytic system on to the PAN support.

The catalysts' dispersions $\left(\mathrm{TiO}_{2}\right.$ and/or $\mathrm{FeSO}_{4}$ in ethanol) were sonicated for $40 \mathrm{~min}$ at $40 \%$ of amplitude and constant temperature by using ultrasonic probe VC505 ${ }^{\circledR}$ of Sonics \& Materials (power of $500 \mathrm{~W}$ and a probe length of $254 \mathrm{~mm}$, Newtown, CT, USA). Then, Dynasylan ${ }^{\circledR} 4144$ was added at $1 \% \mathrm{w} / \mathrm{w}$ of ethanol, followed by a further sonication (15 $\mathrm{min})$.

Similarly, to the electrospinning, the catalysts' dispersion was put in a syringe of $5 \mathrm{~mL}$ volume and then it was electrosprayed onto the preformed electrospun PAN membrane thanks to a voltage generated between the metallic needle and the collector. The whole production process was carried out at room temperature and the humidity was kept constant by flowing dried compressed air.

In the following, membranes are named PAN_TiO, PAN_Fe and PAN_TiO 2 Fe if the catalyst deposited was $\mathrm{TiO}_{2}, \mathrm{FeSO}_{4}$ or $\mathrm{TiO}_{2}+\mathrm{FeSO}_{4}$, respectively. In this work, we referred to homogeneous process when the catalyst $\left(\mathrm{Fe}^{2+}\right)$ and/or oxidant $\left(\mathrm{H}_{2} \mathrm{O}_{2}\right)$ were in the same (liquid) phase of formaldehyde (i.e., they are simply added to formaldehyde solution) while heterogeneous one referred to the use of supported $\mathrm{TiO}_{2}$ and/or Fe catalyst prepared by electro-spinning and -spraying.

Concentrations of catalysts, in both homogeneous and heterogeneous experiments, have been fixed based on optimal compositions reported in literature [11] or based on our previous experience [32]: for homogeneous catalysis, $\mathrm{FeSO}_{4}$ and $\mathrm{H}_{2} \mathrm{O}_{2}$ were used at 24 and 400 ppm, respectively, while in the heterogeneous supported system around $0.15 \mathrm{mg} / \mathrm{cm}^{2}$ of catalyst has been deposited (the exact values are obtained by thermogravimetric analysis (TGA) and are reported in the following).

\subsection{Testing of the Catalytic Systems in the Degradation of Aqueous Formaldehyde Solution}

The set-up used for the experiments is shown in Figure 2. It consisted mainly of a Petri dish with a diameter of $15 \mathrm{~cm}$ and a height of $2 \mathrm{~cm}$, in which $70 \mathrm{~mL}$ of aqueous formaldehyde solution (90 ppm) is placed; a magnetic stirrer provided a good mixing inside the system. The catalytic membrane, comprising titanium dioxide and/or ferrous sulfate, with a $50 \mathrm{~cm}^{2}$ area, was placed on the bottom of the Petri dish and it was kept fixed using eight stainless steel weights. UV irradiation is provided by a lamp (16 W UV Stylo E16, Light Progress, Anghiari, Italy) with a spectral peak centered around $250 \mathrm{~nm}$. The distance between the lamp and the membrane was constant $(2 \mathrm{~cm})$. For some trials, ferrous sulfate was added directly to the aqueous solution. In this case the experiment started after the complete solubilization of the salt into the solution.

The catalytic process lasted $4 \mathrm{~h}$. During the tests, some samples were taken from the aqueous solution. These samples were subjected to a derivatization process according to EPA method 556, before being injected into a GC-MS to quantify formaldehyde content.

It is known that bubbling air within the formaldehyde solution gives some benefits in terms of degradation rate [6] through the electron transfer reaction generating superoxide radical anion:

$$
\mathrm{e}^{-}+\mathrm{O}_{2} \rightarrow \mathrm{O}_{2}^{-} \bullet
$$

However, we preferred to avoid the use of air in order to avoid misleading results due to formaldehyde stripping by the bubbling air. Nonetheless, due to traces of (electron acceptor) impurities or adventitious $\mathrm{O}_{2}$ in the solution (since the solution is in direct contact with ambient air) some superoxide radical anions can still form [6]. 


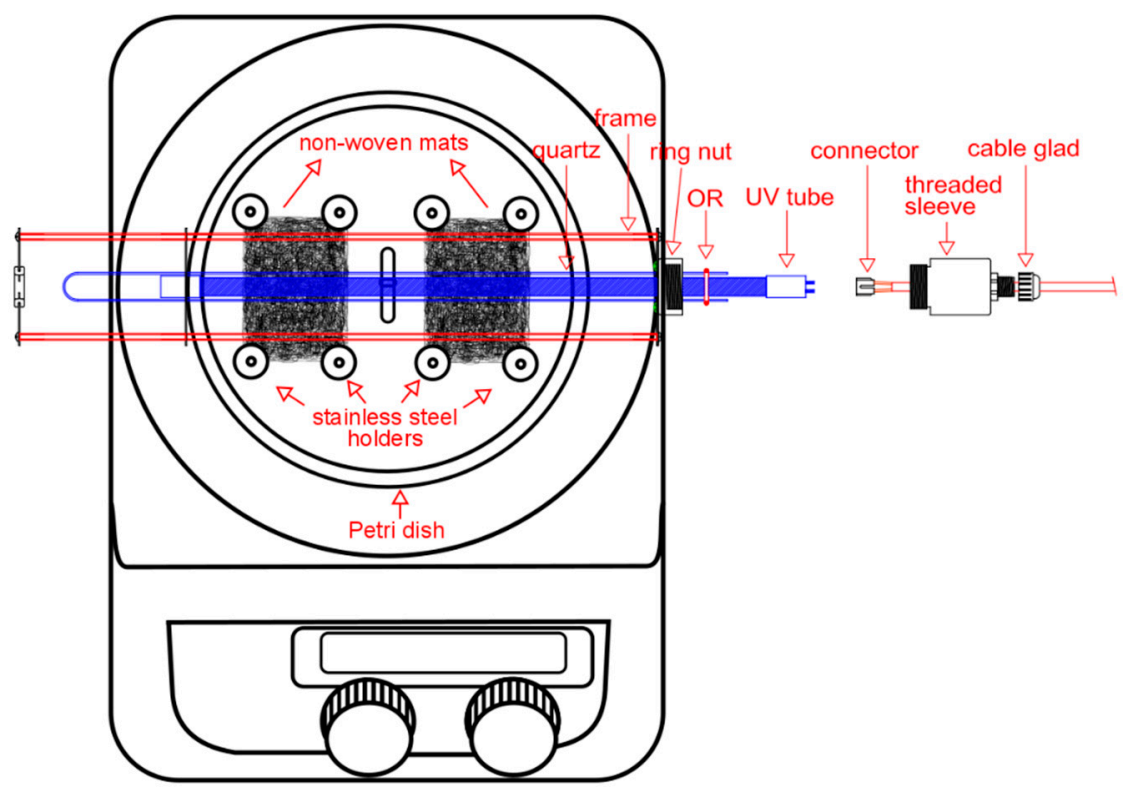

Figure 2. Experimental set-up for testing catalytic activity in formaldehyde degradation.

\subsection{Characterization}

All the membranes are characterized in terms of morphology by scanning electron microscopy (SEM, Obducat CamScan MX2500, Cambridge, UK) and transmission electron microscopy (TEM, FEI model Tecnai G12, Hillsboro, OR, USA). Sample preparation for TEM imaging have been carried out as follows: the membrane samples were embedded in a proper epoxy resin and slices of $100 \mathrm{~nm}$ thickness were obtained by ultramicrotomy of the cured resin.

Furthermore, catalytic content deposited onto the PAN support was investigated through TGA (SDT Q600, TA Instruments, New Castle, DE, USA); the analysis was performed using alumina pan with air flow of $100 \mathrm{cc} / \mathrm{min}$ and a heating rate of $20^{\circ} \mathrm{C} / \mathrm{min}$, from room temperature to $1000{ }^{\circ} \mathrm{C}$.

The quantification of formaldehyde was carried out by withdrawing samples from the aqueous solution during the degradation tests and derivatizing them using o-(2,3,4,5,6-Pentafluorobenzyl)hydroxylamine hydrochloride (PFBHA-HCl). The oxime derivative formed was extracted from water with $4 \mathrm{~mL}$ hexane. The extract was processed through an acidic wash step and then analyzed by GC-MS (Gas Chromatograph Trace $130{ }^{\circledR}$ coupled with the Single Quadrupole Mass Spectrometer ISQ $Q^{\circledR}{ }^{\circledR}$, both purchased from Thermo Scientific, Waltham, MA, USA). The GC column was a non-polar DB5 capillary column ( $0.25 \mathrm{~mm}$ i.d., $30 \mathrm{~m}$ length, supplied by Agilent, Santa Clara, CA, USA). According to the EPA method 556, an internal standard (1,2-dibromopropane) has been used to obtain quantitative data. A calibration curve has also been built before starting the experimental tests, by analyzing formaldehyde solutions of known concentration. The target analytes (oxime derivative, to quantify formaldehyde, and internal standard) were identified (m/z 225 and 121 , respectively) and quantified by using a calibration curve. Each data point has been obtained as the mean value of three replicates.

\section{Results and Discussion}

\subsection{Catalytic Membranes Characterization}

All the produced membranes were characterized by SEM analysis in order to gain a better understanding of the morphology. The SEM micrographs of the PAN and PAN_TiO 2 membranes are reported in Figure 3. It can be observed that PAN nanofibers were smooth, with a mean diameter of $\sim 300 \mathrm{~nm}$. The $\mathrm{TiO}_{2}$ nanoparticles had the tendency to create clusters when spread over the nanofibers 
surface and some large aggregates were formed. However, the catalytic particles had an almost homogeneous distribution upon PAN support without clogging it.

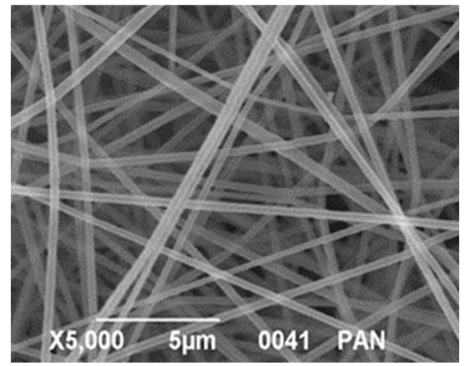

(a)

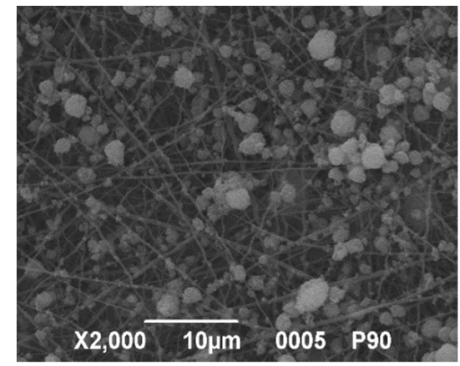

(b)

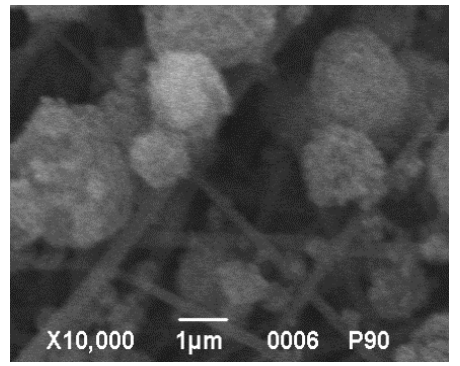

(c)

Figure 3. Scanning electron microscope (SEM) micrographs of (a) PAN, (b,c) $\mathrm{PAN}_{-} \mathrm{TiO}_{2}$ membranes.

TEM images of $\mathrm{PAN}_{-} \mathrm{TiO}_{2}$ are reported in Figure 4. In Figure 4a, the cross sections of the nanofibers can be observed; in Figure $4 \mathrm{~b}, \mathrm{TiO}_{2}$ nanoparticles can be seen around the nanofibers (the cross section of the fiber is not circular due to cutting direction); $\mathrm{TiO}_{2}$ clusters were, mainly, less than $500 \mathrm{~nm}$. From SEM and TEM analysis of PAN_Fe membranes (Figure 5), it was evident that this kind of catalyst also covered almost completely the nanofibers of PAN; in contrast to what happens for $\mathrm{TiO}_{2}$, the clusters had larger dimension and no spherical shape. The difference between the two catalysts is more clear if the TEM image is analysed: ferrous sulfate had bigger dimensions and irregular shape, while $\mathrm{TiO}_{2}$ appeared in spherical clusters with submicron mean diameter.

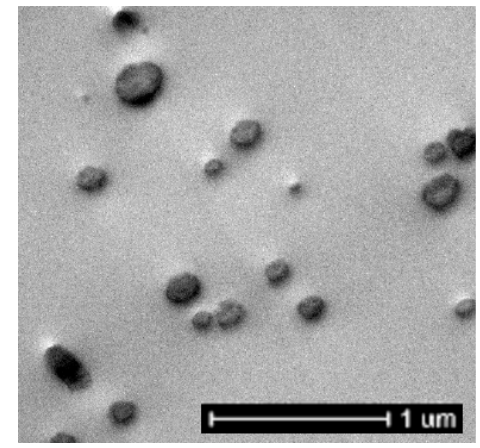

(a)

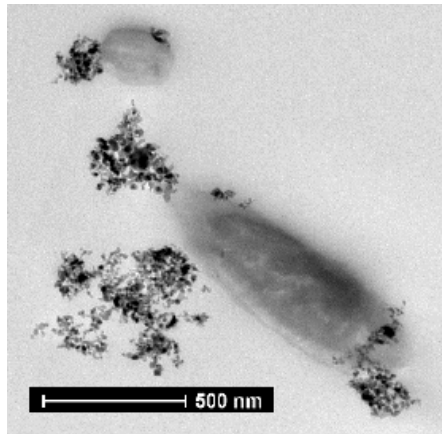

(b)

Figure 4. Transmission electron microscope (TEM) images at different magnifications $(\mathbf{a}, \mathbf{b})$ of PAN_TiO 2 membrane.

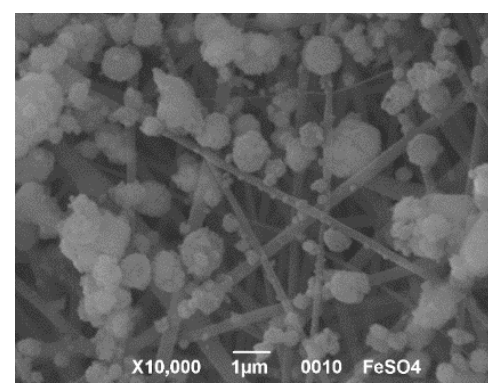

(a)

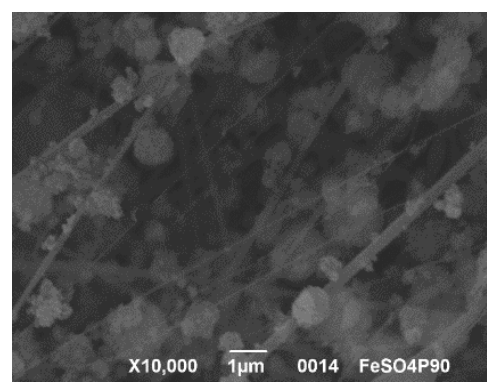

(b)

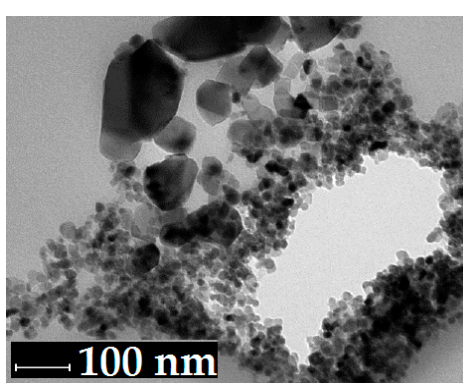

(c)

Figure 5. SEM images of (a) PAN_Fe and (b) $\mathrm{PAN}_{-} \mathrm{TiO}_{2}$ Fe membranes; (c) TEM image of PAN_TiO ${ }_{2}$ Fe membrane. 
The catalyst content of each prepared membrane was measured by TGA analysis, analyzing the residue at high temperature $\left(1000{ }^{\circ} \mathrm{C}\right)$, taking into account that $\mathrm{TiO}_{2}$ did not lose any weight at that temperature while $\mathrm{FeSO}_{4}$ lost $70 \%$ of its initial weight. Based on TGA results, the specific catalyst content for each membrane has been measured; the results are reported in Table 2.

Table 2. Catalyst content of the membranes.

\begin{tabular}{|c|c|}
\hline Membrane & Catalyst Content $\left(\mathrm{mg} / \mathrm{cm}^{2}\right)$ \\
\hline PAN_TiO 2 & 0.14 \\
\hline PAN_Fe & 0.12 \\
\hline \multirow[t]{2}{*}{ PAN_TiO $2 \_F e$} & 0.19 \\
\hline & $\left(53 \% \mathrm{TiO}_{2}+47 \% \mathrm{FeSO}_{4}\right)$ \\
\hline
\end{tabular}

\subsection{Photocatalytic Degradation of the Formaldehyde}

The photocatalytic degradation of formaldehyde, in the presence of $\mathrm{TiO}_{2}$, takes place according to the following reactions (Scheme 1, [33]):

$$
\begin{aligned}
& \mathrm{TiO}_{2}+\mathrm{hv} \rightarrow \mathrm{e}^{-}+\mathrm{h}^{+} \\
& \mathrm{h}^{+}+\mathrm{OH}^{-} \rightarrow \mathrm{OH} \bullet \\
& \mathrm{e}^{-}+\mathrm{O}_{2} \rightarrow \mathrm{O}_{2}^{-} \bullet \\
& \mathrm{OH} \bullet+\mathrm{CH}_{2} \mathrm{O} \rightarrow \mathrm{H}_{2} \mathrm{O}+\mathrm{CHO} \bullet \\
& \mathrm{CHO} \bullet+\mathrm{OH} \bullet \rightarrow \mathrm{HCOOH} \\
& \mathrm{CHO} \bullet+\mathrm{O}_{2}^{-} \bullet \rightarrow \mathrm{HCO}_{3}^{-} \stackrel{\mathrm{H}^{+}}{\rightarrow} \mathrm{HCOOOH} \stackrel{\mathrm{CH}_{2} \mathrm{O}}{\rightarrow} 2 \mathrm{HCOOH} \\
& \mathrm{HCOOH} \stackrel{-\mathrm{H}^{+}}{\longrightarrow} \mathrm{HCOO}^{-} \stackrel{\mathrm{OH} \bullet}{\longrightarrow} \mathrm{H}_{2} \mathrm{O}+\mathrm{CO}_{2}^{-} \bullet \\
& \mathrm{HCOO}^{-} \stackrel{\mathrm{h}^{+}}{\longrightarrow} \mathrm{H}^{+}+\mathrm{CO}_{2}^{-} \bullet \\
& \mathrm{CO}_{2}^{-} \bullet \stackrel{[\mathrm{O}],[\mathrm{OH} \bullet], \mathrm{h}^{+}}{\longrightarrow} \mathrm{CO}_{2}
\end{aligned}
$$

Scheme 1. Mechanism of photocatalytic degradation of formaldehyde in aqueous solution.

The results for catalytic degradation with $\mathrm{PAN} \_\mathrm{TiO}_{2}$ membrane are reported in Figure 6; $\mathrm{PAN} \mathrm{TiO}_{2}$ membrane contained $0.14 \mathrm{mg} / \mathrm{cm}^{2}$ of $\mathrm{TiO}_{2}$ (i.e., optimal composition defined elsewhere [32]) which corresponded to a total amount of $\mathrm{TiO}_{2}$ of $7 \mathrm{mg}$ in the system. 


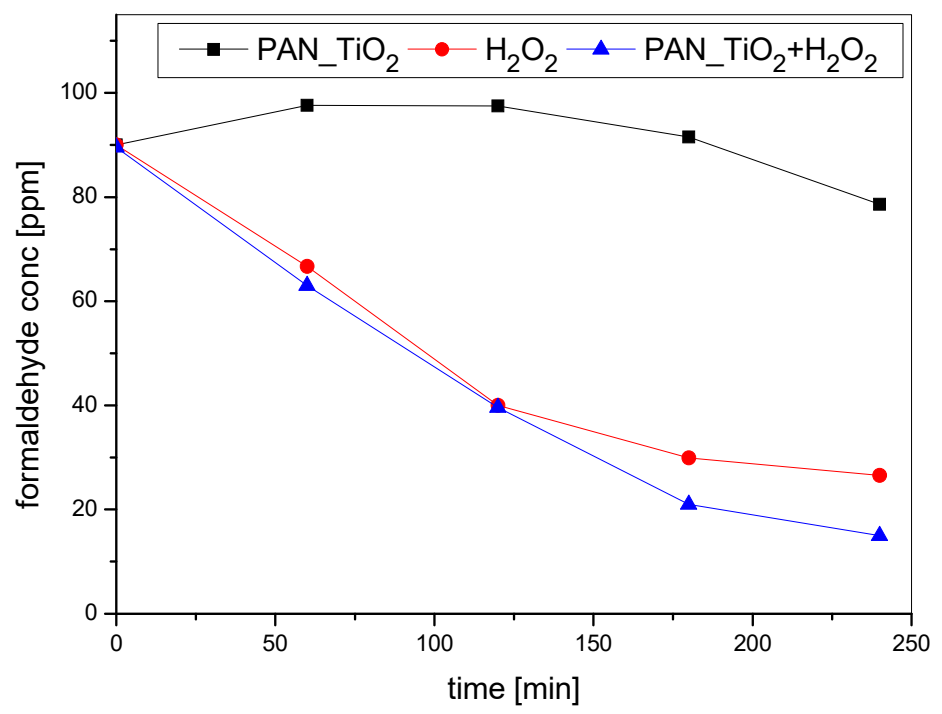

Figure 6. Formaldehyde concentration during photocatalytic experiment with and without added $\mathrm{H}_{2} \mathrm{O}_{2}$ (400 ppm). The maximum standard deviation of the experimental points was $1.9 \mathrm{ppm}$.

For heterogeneous catalytic system $\mathrm{PAN}_{-} \mathrm{TiO}_{2}$, an increase in the formaldehyde content was observed during the first stage of degradation. This can be rationalized considering that the degradation of methanol (which was contained at $10 \mathrm{wt} \%$ in the formalin solution as stabilizer to limit formaldehyde polymerization) led to the formation of formaldehyde, according to the following reactions (Scheme 2, [34]):

$$
\begin{aligned}
\mathrm{CH}_{3} \mathrm{OH}+\mathrm{OH} \bullet & \rightarrow \bullet \mathrm{CH}_{2} \mathrm{OH}+\mathrm{H}_{2} \mathrm{O} \\
\bullet \mathrm{CH}_{2} \mathrm{OH}+\mathrm{O}_{2} & \rightarrow \mathrm{CH}_{2} \mathrm{O}+\mathrm{HO}_{2} \bullet \\
\mathrm{CH}_{2} \mathrm{O}+\mathrm{OH} \bullet & \rightarrow \mathrm{HCOOH}+\mathrm{H} \bullet
\end{aligned}
$$

Scheme 2. Methanol photocatalytic degradation path.

The degradation of the methanol can start as soon as a hydroxyl radical is produced and it may compete with formaldehyde to consume hydroxyl radicals resulting in the retardation of the oxidation reaction of formaldehyde. Both methanol and formaldehyde formed formic acid during their degradation. Indeed, the initial $\mathrm{pH}$ of the solution was around $6.5-7$, and it was not adjusted, owing to the $\mathrm{pH}$-independent photocatalytic activity of $\mathrm{TiO}_{2}$ [19], but during the test, it decreased to 4.2 and then rose to 5, as already reported in similar studies [6,7], thus implying the formation of formic acid. Therefore, we can assess that, since both methanol and formaldehyde were oxidized to formic acid (and then to $\mathrm{CO}_{2}$ and water), these compounds were responsible for the drop in the $\mathrm{pH}$ of the solution. As $\mathrm{CO}_{2}$ was liberated from the solution, $\mathrm{pH}$ increased [7].

However, it was evident that after $4 \mathrm{~h}$ the abatement of the formaldehyde content was still low.

The addition of $\mathrm{H}_{2} \mathrm{O}_{2}$ (400 ppm, according to optimal content reported in [11]) in aqueous solution to the $\mathrm{PAN}-\mathrm{TiO}_{2}$ system (PAN_TiO ${ }_{2}+\mathrm{H}_{2} \mathrm{O}_{2}$ in Figure 6) resulted in greater oxidation with respect to neat $\mathrm{PAN}-\mathrm{TiO}_{2}$ and this was likely attributed to the enhanced charge separation induced by $\mathrm{H}_{2} \mathrm{O}_{2}$ as an electron acceptor and the reductive conversion of $\mathrm{H}_{2} \mathrm{O}_{2}$ to $\mathrm{OH} \bullet$ [7]. Moreover, the methanol degradation was very fast and the increase in the formaldehyde content was not revealed (since the first sampling point was after $1 \mathrm{~h}$ ).

Comparing homogeneous system using $\mathrm{H}_{2} \mathrm{O}_{2}$ only (400 ppm, without catalytic membrane, curve $\mathrm{H}_{2} \mathrm{O}_{2}$ in Figure 6) with the previous heterogeneous one ( $\left.\mathrm{PAN}_{-} \mathrm{TiO}_{2}+\mathrm{H}_{2} \mathrm{O}_{2}\right)$, it can be noted that the higher removal rate was mainly due, especially in the first $2 \mathrm{~h}$, to the direct oxidation of $\mathrm{H}_{2} \mathrm{O}_{2}$ onto the organic substrate. The trend of the degradation of formaldehyde with only $\mathrm{H}_{2} \mathrm{O}_{2}$ was very similar to that reported by Guimarães et al. [7]. Since also in $\mathrm{H}_{2} \mathrm{O}_{2}$-system the $\mathrm{pH}$ decreased from 6.5 to 3.8, 
the formation of formic acid can still be speculated. After the $\mathrm{H}_{2} \mathrm{O}_{2}$ was completely consumed, the degradation reaction stopped and the $\mathrm{CH}_{2} \mathrm{O}$ concentration reached a plateau while in the presence of $\mathrm{TiO}_{2}$ it seemed to further decrease.

\subsection{Photo-Fenton Degradation of Formaldehyde}

Photo-Fenton degradation of formaldehyde was also studied. Several catalytic, homogeneous and heterogeneous systems have been compared, to gain deep understanding of the process. In this work, we referred to homogeneous process when the catalyst $\left(\mathrm{Fe}^{2+}\right)$ and/or oxidant $\left(\mathrm{H}_{2} \mathrm{O}_{2}\right)$ were in the same (liquid) phase of formaldehyde while the heterogeneous one referred to the use of supported Fe catalyst.

Generally speaking, photo-Fenton systems are based on the contemporary use of Fe ions and hydrogen peroxide: ferrous ions react with hydrogen peroxide under the irradiation of UV light, producing hydroxyl radicals with powerful oxidizing abilities. While in the Fenton reaction $\mathrm{Fe}^{3+}$ ions accumulate in the system and the reaction stops once all $\mathrm{Fe}^{2+}$ ions are consumed, in the photo-Fenton reaction the regeneration of ferrous ions by photo-reduction of ferric ions occurs according to Scheme 3 :

$$
\begin{gathered}
\mathrm{Fe}^{2+}+\mathrm{H}_{2} \mathrm{O}_{2} \rightarrow \mathrm{Fe}^{3+}+\mathrm{OH}^{-}+\mathrm{OH} \bullet \\
\mathrm{Fe}^{3+}+\mathrm{hu}+\mathrm{H}_{2} \mathrm{O} \rightarrow \mathrm{OH} \bullet+\mathrm{Fe}^{2+}+\mathrm{H}^{+}
\end{gathered}
$$

Scheme 3. Photo-Fenton reactions.

The newly generated ferrous ions react again with $\mathrm{H}_{2} \mathrm{O}_{2}$ generating hydroxyl radical and ferric ion and, in this way, the cycle continues. Therefore, the rate of degradation of organic pollutants in photo-Fenton reaction increases with respect to the Fenton one [35]. The photo-Fenton process offers better performance at $\mathrm{pH} 3.0$, when the hydroxyl- $-\mathrm{Fe}^{3+}$ complexes are more soluble and $\mathrm{Fe}(\mathrm{OH})^{2+}$ is more photoactive [36]. However, although ferrous ions are regenerated, generally, a large amount of $\mathrm{H}_{2} \mathrm{O}_{2}$ needs to be irreversibly consumed.

Results for formaldehyde degradation in a homogeneous photo-Fenton process, with and without added $\mathrm{H}_{2} \mathrm{O}_{2}\left(\mathrm{Fe} / \mathrm{H}_{2} \mathrm{O}_{2}\right.$ and Fe curves, respectively) as well as heterogeneous one (PAN_Fe curve) are reported in Figure 7; homogeneous photolytic oxidation $\left(\mathrm{H}_{2} \mathrm{O}_{2}\right.$ curve in Figure 7$)$ is also reported for comparison. In photo-Fenton processes (i.e., whenever Fe was present) the $\mathrm{pH}$ has been adjusted to 3 using $0.2 \mathrm{~N}$ sulfuric acid. When ferrous sulfate and $\mathrm{H}_{2} \mathrm{O}_{2}$ were used in solution, their concentrations were 24 and 400 ppm, respectively, i.e., set at the optimal conditions identified elsewhere [11]. The heterogeneous PAN-Fe catalyst comprised $0.12 \mathrm{mg} / \mathrm{cm}^{2}$ of $\mathrm{FeSO}_{4}$ (i.e., similar content to the $\mathrm{TiO}_{2}$ content of the previous experiment, i.e., optimal composition defined elsewhere [32]), which corresponded to a total of $6 \mathrm{mg}$ of ferrous sulfate in the system. All the trials have been carried out under UV irradiation; it shall be kept in mind that in presence of iron sulfate the UV absorbance of the system around $290 \mathrm{~nm}$ was quite high, owing to the absorption properties of this compound [23].

Within the homogeneous processes (curves $\mathrm{Fe}, \mathrm{H}_{2} \mathrm{O}_{2}$ and $\mathrm{Fe} / \mathrm{H}_{2} \mathrm{O}_{2}$ in Figure 7), the photo-Fenton $\mathrm{Fe} / \mathrm{H}_{2} \mathrm{O}_{2}$ demonstrated the best performance; however, also the use of iron compound alone (Fe curve), without adding $\mathrm{H}_{2} \mathrm{O}_{2}$, gave good results since the final formaldehyde concentration was the same as for $\mathrm{Fe} / \mathrm{H}_{2} \mathrm{O}_{2}$, although the initial rate was lower. Similar results have already been reported by other authors $[29,37]$ for different compounds, i.e., the addition of $\mathrm{H}_{2} \mathrm{O}_{2}$ to Fe catalyst was beneficial, but the degradation took place also without adding $\mathrm{H}_{2} \mathrm{O}_{2}$. 


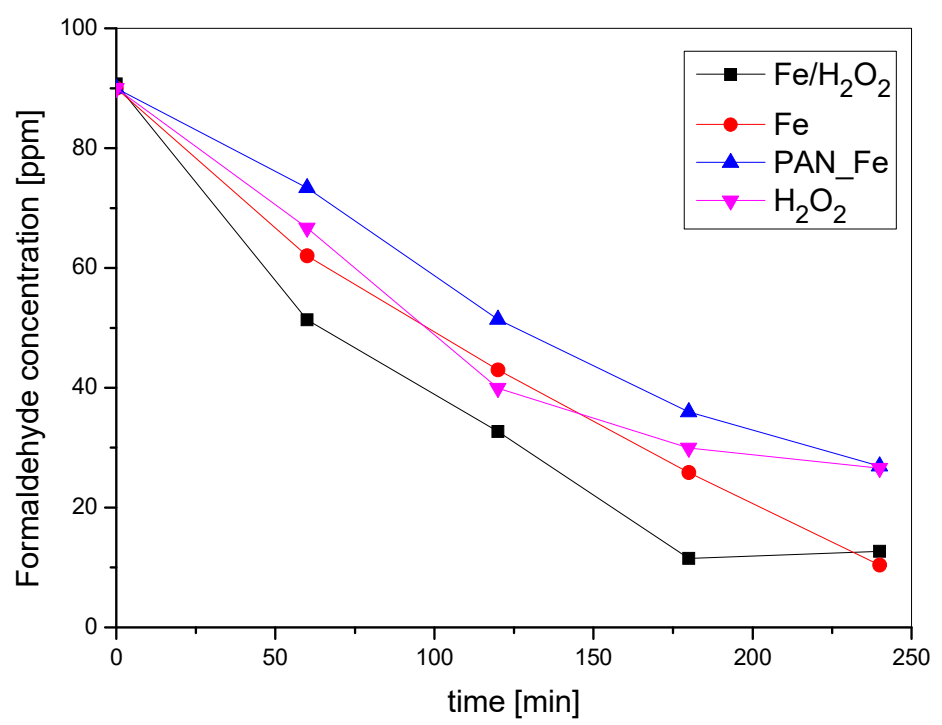

Figure 7. Formaldehyde concentration during photolysis and photo-Fenton experiment. The maximum standard deviation of the experimental points was $2.5 \mathrm{ppm}$.

There can be several reasons for this. First, it should also be kept in mind that small amount of $\mathrm{H}_{2} \mathrm{O}_{2}$ can also be developed during UV irradiation of formaldehyde [9]. Secondly, ferrous ion can react with dissolved oxygen in water (Scheme 4) forming reactive oxidants capable of oxidative degradation. Indeed, superoxide radical anions can form, by reaction of $\mathrm{Fe}^{2+}$ with oxygen of the air dissolved into the solution [6], leading to the formation of $\mathrm{H}_{2} \mathrm{O}_{2}$ [38]; moreover, $\mathrm{Fe}^{2+}$ in the UV light conditions, can be partially transformed into $\mathrm{Fe}^{3+}$, the $\mathrm{Fe}^{3+}$ in solution can be hydrolyzed to hydroxylable $\mathrm{Fe}(\mathrm{OH})^{2+}$, $\mathrm{Fe}(\mathrm{OH})^{2+}$ also can be transformed into $\mathrm{Fe}^{2+}$ under ultraviolet light, while producing $\mathrm{OH}$ radicals to form a $\mathrm{Fe}^{3+} / \mathrm{Fe}^{2+}$ cycle of reactions $[11,39,40]$ :

$$
\begin{gathered}
\mathrm{Fe}^{2+}+\mathrm{O}_{2} \rightarrow \mathrm{Fe}^{3+}+\mathrm{O}_{2}^{-} \bullet \\
\mathrm{Fe}^{2+}+\mathrm{O}_{2}^{-} \bullet+2 \mathrm{H}^{+} \rightarrow \mathrm{Fe}^{3+}+\mathrm{H}_{2} \mathrm{O}_{2} \\
\mathrm{Fe}^{3+}+\mathrm{H}_{2} \mathrm{O} \rightarrow \mathrm{Fe}(\mathrm{OH})^{2+}+\mathrm{H}^{+} \\
\mathrm{Fe}(\mathrm{OH})^{2+} \rightarrow \mathrm{Fe}^{2+}+\mathrm{OH} \bullet
\end{gathered}
$$

Scheme 4. Reactions between ferrous ion and dissolved oxygen.

Therefore, in the presence of $\mathrm{Fe}^{2+}$ and UV light several reactions can take place to generate oxidizing species $\left(\mathrm{OH} \bullet, \mathrm{O}_{2}^{-} \bullet\right.$ and $\mathrm{H}_{2} \mathrm{O}_{2}$ ) without the need to add external hydrogen peroxide.

Lastly, it could also be possible that the formic acid, deriving from degradation of formaldehyde, created a complex compound with iron [41] which could be photolyzed and even photocatalyzed in the reaction medium, generating $\mathrm{Fe}^{2+}, \mathrm{H}_{2} \mathrm{O}_{2}$ and other active radical species [38], in a similar way to that reported for oxalic acid by Quici et al. [26].

The effectiveness of Fe catalyst also without $\mathrm{H}_{2} \mathrm{O}_{2}$ is very important since avoiding the use of $\mathrm{H}_{2} \mathrm{O}_{2}$ makes the process more economic and safer.

Also, a heterogeneous photo-Fenton process, i.e., using a supported Fe catalyst (PAN_Fe), has been shown to be active in formaldehyde degradation; however, as expected, the reaction rate was slower with respect to homogenous systems. This PAN_Fe system reached the same final formaldehyde content as photolytic oxidation $\left(\mathrm{H}_{2} \mathrm{O}_{2}\right.$ curve) process (but without the use of costly and hazardous reagents like water peroxide) and only slightly higher concentration than homogenous photo-Fenton processes. 


\subsection{Photo-Catalytic-Fenton Degradation of Formaldehyde}

After the separate analysis of photocatalytic and photo-Fenton processes, the combination of such AOPs has been studied.

Figure 8 reports the results when using a heterogeneous system based on photo-Fenton (PAN_Fe), photocatalysis ( $\mathrm{PAN} \_\mathrm{TiO}_{2}$ ) and their combination ( $\left.\mathrm{PAN} \_\mathrm{TiO}_{2} \_\mathrm{Fe}\right)$, under $\mathrm{UV}$ illumination, $\mathrm{pH}=3$, without the use of any added $\mathrm{H}_{2} \mathrm{O}_{2}$. It can be noted that the combination of $\mathrm{TiO}_{2}$ and $\mathrm{Fe}^{2+}$ showed the best result, i.e., there was a synergy deriving from the combination of photocatalysis and photo-Fenton since the combined process gave better results than the simple sum of the two distinct processes.

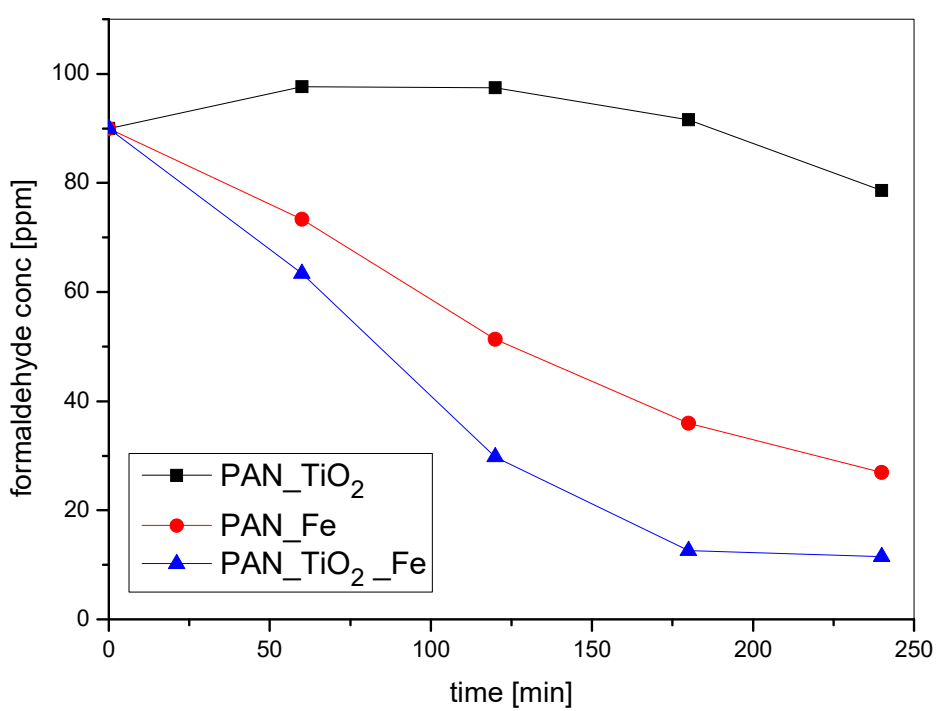

Figure 8. Formaldehyde concentration profile using heterogeneous photo-Fenton (PAN_Fe), photocatalytic $\left(\mathrm{PAN} \_\mathrm{TiO}_{2}\right)$ and their combination $\left(\mathrm{PAN} \_\mathrm{TiO}_{2} \_\mathrm{Fe}\right)$ catalysts. The maximum standard deviation of the experimental points was $1.9 \mathrm{ppm}$.

This synergy can be due to the fact that in presence of iron sulfate the UV absorbance of the system around $290 \mathrm{~nm}$ increased, owing to the absorption properties of this compound, therefore favoring UV activation [23]. Moreover, this synergy can be related to the roles of iron as an electron acceptor, to facilitate charge separation in $\mathrm{TiO}_{2}$ photocatalyst, thereby reducing the non-desired electron/hole recombination and thus increasing the rate of $\mathrm{OH} \bullet$ formation through the first and second reaction in Scheme 1. Similar results have been reported for homogeneous $\mathrm{TiO}_{2}-\mathrm{Fe}$ system in phenol degradation [19], for Azo dye [25] and for bisphenol A [15] and for Fe doped $\mathrm{TiO}_{2}$ [20,21,23].

It was also reported that in this system $\mathrm{TiO}_{2}$ is beneficial to the fast conversion of $\mathrm{Fe}^{3+} \rightarrow \mathrm{Fe}^{2+}$ [15], thus favoring the closing the $\mathrm{Fe}^{3+} / \mathrm{Fe}^{2+}$ cycle of reactions mentioned before when dealing with photo-Fenton. Also, the accumulated electrons in the conduction band of $\mathrm{TiO}_{2}$ are transferred to oxygen (coming from the air in contact with formaldehyde solution) on the $\mathrm{TiO}_{2}$ surface for the formation of $\mathrm{O}^{2-}$ or $\mathrm{O}_{2}{ }^{2-}$, which combines with $\mathrm{H}^{+}$to form $\mathrm{H}_{2} \mathrm{O}_{2}$ [28]. The evolved $\mathrm{H}_{2} \mathrm{O}_{2}$ with $\mathrm{FeSO}_{4}$ formed Fenton reagent which can further degrade formaldehyde [28].

Summarizing, the presence of iron was beneficial in promoting the photocatalytic activity of $\mathrm{TiO}_{2}$ while $\mathrm{TiO}_{2}$ was beneficial in promoting the photo-Fenton reaction.

If we compare the results obtained with a fully heterogeneous system $\left(\mathrm{PAN}_{-} \mathrm{TiO}_{2} \mathrm{Fe}\right.$, where $\mathrm{Fe}$ is deposited onto the support) and partly homogeneous one ( $\mathrm{PAN}_{-} \mathrm{TiO}_{2}+\mathrm{Fe}$, where $24 \mathrm{ppm}$ of ferrous sulfate was in the aqueous solution, as before in photo-Fenton trials) (Figure 9), it can be noted that the degradation rate was slightly faster for the latter, probably owing to a higher photo-Fenton reaction rate; however, both systems reached a final $\mathrm{CH}_{2} \mathrm{O}$ concentration of around $10 \mathrm{ppm}$. 


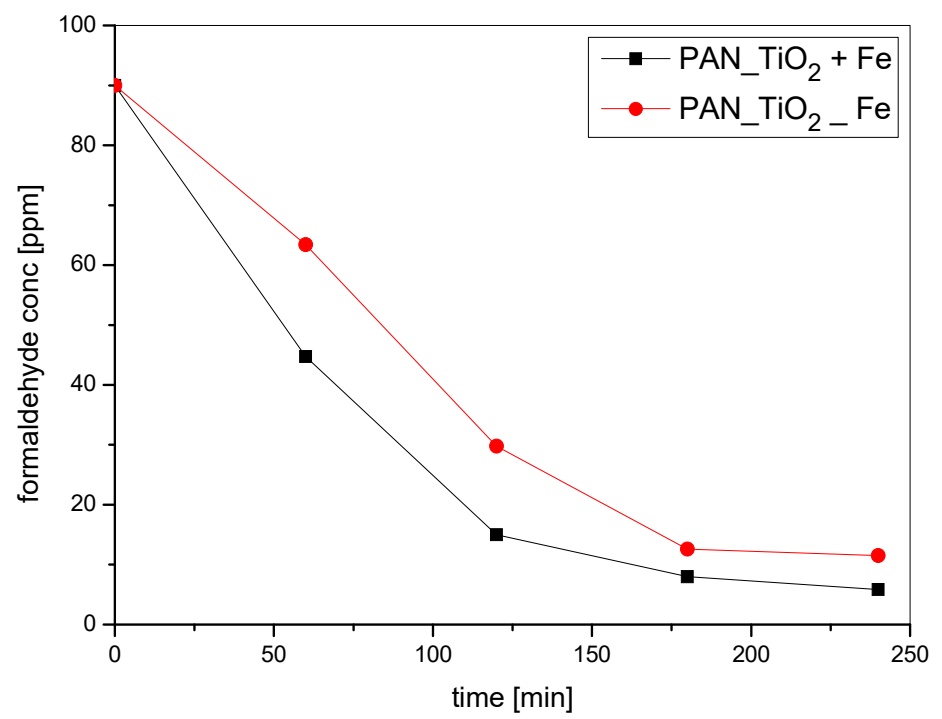

Figure 9. Formaldehyde concentration profile using heterogeneous photo-catalytic-Fenton with Fe supported (PAN_TiO 2 _Fe) or dispersed in solution $\left(\mathrm{PAN}_{-} \mathrm{TiO}_{2}+\mathrm{Fe}\right)$. The maximum standard deviation of the experimental points was $1.8 \mathrm{ppm}$.

However, if we compare the results on a catalyst weight basis, i.e., considering the moles of formaldehyde degraded per mg of catalyst, it can be shown (Figure 10) that up to $3 \mathrm{~h}$ there were no significant differences for PAN_Fe and $\mathrm{PAN}_{-} \mathrm{TiO}_{2} \mathrm{Fe}$; however, over a longer period the best performing system was PAN_Fe. Obviously, this was an initial work and further studies on the optimal iron content need to be carried out.

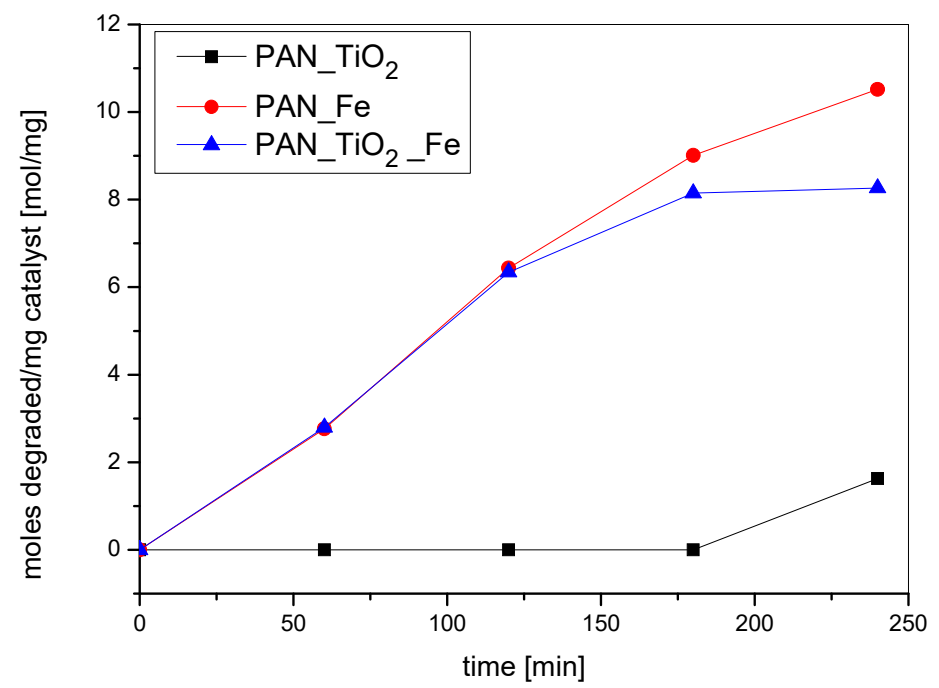

Figure 10. Formaldehyde degraded per mg of catalyst for heterogeneous photo-Fenton (PAN_Fe), photocatalytic $\left(\mathrm{PAN} \_\mathrm{TiO}_{2}\right)$ and their combination $\left(\mathrm{PAN}_{-} \mathrm{TiO}_{2} \_\mathrm{Fe}\right)$ catalysts.

\section{Conclusions}

Photocatalytic and photo-Fenton processes as well as their combination were studied to degrade formaldehyde aqueous solution; both homogeneous and heterogeneous catalysts were used.

The results showed that the combination of AOPs gave a synergy since the presence of iron was beneficial in promoting the photocatalytic activity of $\mathrm{TiO}_{2}$ while $\mathrm{TiO}_{2}$ was beneficial in promoting the photo-Fenton reaction. 
Moreover, very good results have been obtained using fully heterogeneous nanostructured catalysts (based on $\mathrm{TiO}_{2}$ and $\mathrm{FeSO}_{4}$ ) without the need to add $\mathrm{H}_{2} \mathrm{O}_{2}$. In this way, a more economic formaldehyde treatment process has been developed.

Author Contributions: Conceptualization, R.B., M.R., A.M. and A.L.; Data curation, R.B. and C.B.; Funding acquisition, A.L.; Investigation, C.B. and L.C.; Methodology, R.B., M.R., A.M. and A.L.; Project administration, A.L.; Supervision, R.B.; Visualization, R.B.; Writing-original draft, R.B., C.B. and L.C.; Writing-review and editing, M.R., A.M., M.M. and A.L. All authors have read and agreed to the published version of the manuscript.

Funding: The research leading to these results has received funding from University of Padova, Department of Industrial Engineering, Twinning Project 2017.

Conflicts of Interest: The authors declare no conflict of interest.

\section{References}

1. Bennett, M. TICs, TIMs, and Terrorists. Today's Chem. Work 2003, 12, 21-25.

2. Raja Priya, K.; Sandhya, S.; Swaminathan, K. Kinetic analysis of treatment of formaldehyde containing wastewater in UAFB reactor. Chem. Eng. J. 2009, 148, 212-216. [CrossRef]

3. Deng, Y.; Zhao, R. Advanced Oxidation Processes (AOPs) in Wastewater Treatment. Curr. Pollut. Rep. 2015, 1, 167-176. [CrossRef]

4. Dong, C.P.H.C.; Tang, Z. Advanced chemical oxidation: Its present role and potential future in hazardous waste treatment. Waste Manag. 1993, 13, 361-377.

5. Pignatello, J.J.; Oliveros, E.; MacKay, A. Advanced oxidation processes for organic contaminant destruction based on the fenton reaction and related chemistry. Crit. Rev. Environ. Sci. Technol. 2006, 36, 1-84. [CrossRef]

6. Shin, E.M.; Senthurchelvan, R.; Munoz, J.; Basak, S.; Rajeshwar, K.; Benglas-Smith, G.; Howell, B.C. Photolytic and photocatalytic destruction of formaldehyde in aqueous media. J. Electrochem. Soc. 1996, 143, 1562-1570. [CrossRef]

7. Guimarães, J.R.; Turato Farah, C.R.; Maniero, M.G.; Fadini, P.S. Degradation of formaldehyde by advanced oxidation processes. J. Environ. Manag. 2012, 107, 96-101. [CrossRef]

8. Sifang, L.; Guoliang, Y.; Guoqin, C. Low-temperature preparation and characterization of nanocrystalline anatase $\mathrm{TiO}_{2}$. J. Phys. Chem. C 2009, 113, 4031-4037.

9. Shiraishi, F.; Nakasako, T.; Hua, Z. Formation of Hydrogen Peroxide in Photocatalytic Reactions. J. Phys. Chem. A 2003, 107, 11072-11081. [CrossRef]

10. Kabra, K.; Chaudhary, R.; Sawhney, R.L. Treatment of hazardous organic and inorganic compounds through aqueous-phase photocatalysis: A review. Ind. Eng. Chem. Res. 2004, 43, 7683-7696. [CrossRef]

11. Liang, J.; Liu, X.; Zhang, Z.; Wang, Y. Kinetics and Reaction Mechanism for Formaldehyde Wastewater Using UV-Fenton Oxidation. In Proceedings of the 2010 4th International Conference on Bioinformatics and Biomedical Engineering (CBBE), Chengdu, China, 18-20 June 2010; IEEE: Piscataway, NJ, USA, 2010; pp. 1-5.

12. Kajitvichyanukul, P.; Lu, M.C.; Jamroensan, A. Formaldehyde degradation in the presence of methanol by photo-Fenton process. J. Environ. Manag. 2008, 86, 545-553. [CrossRef] [PubMed]

13. Pang, H.C.; Fu, H.Y.; Gao, T.Z. Treatment of high concentration wastewater containing phenols and aldehyde from a small Phenolic resin plant. Adv. Mater. Res. 2014, 864-867, 1552-1555. [CrossRef]

14. Lazar, M.A.; Varghese, S.; Nair, S.S. Photocatalytic Water Treatment by Titanium Dioxide: Recent Updates. Catalysts 2012, 2, 572-601. [CrossRef]

15. Xu, L.; Meng, L.; Zhang, X.; Mei, X.; Guo, X.; Li, W.; Wang, P.; Gan, L. Promoting $\mathrm{Fe}^{3+} / \mathrm{Fe}^{2+}$ cycling under visible light by synergistic interactions between P25 and small amount of Fenton reagents. J. Hazard. Mater. 2019, 379, 120795. [CrossRef] [PubMed]

16. Gogate, P.R.; Pandit, A.B. A review of imperative technologies for wastewater treatment II: Hybrid methods. Adv. Environ. Res. 2004, 8, 553-597. [CrossRef]

17. Adewu-Yi, Y.G. Sonochemistry in environmental remediation. 2. Heterogeneous sonophotocatalytic oxidation processes for the treatment of pollutants in water. Environ. Sci. Technol. 2005, 39, 8557-8570. [CrossRef]

18. Mokhbi, Y.; Korichi, M.; Akchiche, Z. Combined photocatalytic and Fenton oxidation for oily wastewater treatment. Appl. Water Sci. 2019, 9, 35. [CrossRef] 
19. Kim, H.E.; Lee, J.; Lee, H.; Lee, C. Synergistic effects of $\mathrm{TiO}_{2}$ photocatalysis in combination with Fenton-like reactions on oxidation of organic compounds at circumneutral pH. Appl. Catal. B Environ. 2012, 115-116, 219-224. [CrossRef]

20. Khanmohammadi, M.; Bagheri, A.; Elmizadeh, H. Spectrophotometric evaluation of the photocatalytic degradation of formaldehyde by $\mathrm{Fe}_{2} \mathrm{O}_{3}-\mathrm{TiO}_{2}$ nano hybrid. J. Ind. Eng. Chem. 2014, 20, 1841-1844. [CrossRef]

21. Siddhapara, K.; Shah, D. Study of photocatalytic activity and magnetic properties of Co, Mn metal ions doped nanocrystalline $\mathrm{TiO}_{2}$ prepared by Sol-Gel method. J. Cryst. Growth 2016, 452, 158-161. [CrossRef]

22. Li, J.; Ren, D.; Wu, Z.; Xu, J.; Bao, Y.; He, S.; Chen, Y. Flame retardant and visible light-activated Fe-doped $\mathrm{TiO}_{2}$ thin films anchored to wood surfaces for the photocatalytic degradation of gaseous formaldehyde. J. Colloid Interface Sci. 2018, 530, 78-87. [CrossRef] [PubMed]

23. Cheng, S.W.; Li, Y.H.; Yuan, C.S.; Tsai, P.Y.; Shen, H.Z.; Hung, C.H. An innovative advanced oxidation technology for effective decomposition of formaldehyde by combining iron modified nano- $\mathrm{TiO}_{2}\left(\mathrm{Fe} / \mathrm{TiO}{ }_{2}\right)$ photocatalytic degradation with ozone oxidation. Aerosol Air Qual. Res. 2018, 18, 3220-3233. [CrossRef]

24. Chun, H.H.; Lee, J.Y.; Jo, W.K. Photocatalysis of low-concentration gaseous organic pollutants over electrospun iron-doped titanium dioxide nanofibers. Solid State Sci. 2013, 25, 103-109. [CrossRef]

25. Bouras, P.; Lianos, P. Synergy effect in the combined photodegradation of an azo dye by titanium dioxide photocatalysis and photo-fenton oxidation. Catal. Lett. 2008, 123, 220-225. [CrossRef]

26. Quici, N.; Morgada, M.E.; Piperata, G.; Babay, P.; Gettar, R.T.; Litter, M.I. Oxalic acid destruction at high concentrations by combined heterogeneous photocatalysis and photo-Fenton processes. Catal. Today 2005, 101, 253-260. [CrossRef]

27. Shao, L.; Hu, B.; Dong, P.; Ji, W.; Qi, C. Electrospinning Fe(III)porphyrin/TiO2/poly(styrene) mixture:formation of a novel nanofiber photocatalyst for the photodegradation of methyl orange. J. Porphyr. Phthalocyanines 2010, 14, 993-999. [CrossRef]

28. Zhang, Y.G.; Ma, L.L.; Li, J.L.; Yu, Y. In situ Fenton reagent generated from $\mathrm{TiO}_{2} / \mathrm{Cu}_{2} \mathrm{O}$ composite film: A new way to utilize $\mathrm{TiO}_{2}$ under visible light irradiation. Environ. Sci. Technol. 2007, 41, 6264-6269. [CrossRef]

29. Zhu, T.; Ong, W.L.; Zhu, L.; Ho, G.W. $\mathrm{TiO}_{2}$ fibers supported $\beta$-FeOOH nanostructures as efficient visible light photocatalyst and room temperature sensor. Sci. Rep. 2015, 5, 10601. [CrossRef]

30. Keulemans, M.; Verbruggen, S.W.; Hauchecorne, B.; Martens, J.A.; Lenaerts, S. Activity versus selectivity in photocatalysis: Morphological or electronic properties tipping the scale. J. Catal. 2016, 344, 221-228. [CrossRef]

31. Kete, M.; Pavlica, E.; Fresno, F.; Bratina, G.; Štangar, U.L. Highly active photocatalytic coatings prepared by a low-temperature method. Environ. Sci. Pollut. Res. 2014, 21, 11238-11249. [CrossRef]

32. Modesti, M.; Roso, M.; Boaretti, C.; Besco, S.; Hrelja, D.; Sgarbossa, P.; Lorenzetti, A. Preparation of smart nano-engineered electrospun membranes for methanol gas-phase photoxidation. Appl. Catal. B Environ. 2014, 144, 216-222. [CrossRef]

33. Yang, J.; Li, D.; Zhang, Z.; Li, Q.; Wang, H. A study of the photocatalytic oxidation of formaldehyde on $\mathrm{Pt} / \mathrm{Fe}_{2} \mathrm{O}_{3} / \mathrm{TiO}_{2}$. J. Photochem. Photobiol. A Chem. 2000, 137, 197-202. [CrossRef]

34. Arana, J.; Nieto Martinez, J.A.; Herrera Melian, J.A.; Dona Rodriguez, J.M.; Gonzalez Diaz, O.; Perez Pena, J.; Bergasa, O.; Alvarez, C.; Mendez, J. Photocatalytic degradation of formaldehyde containing wastewater from veterinarian laboratories endez. Chemosphere 2004, 55, 893-904. [CrossRef] [PubMed]

35. Kim, S.M.; Vogelpohl, A. Degradation of Organic Pollutants by the Photo-Fenton-Process. Chem. Eng. Technol. 1998, 21, 187-191. [CrossRef]

36. Ameta, R.; Chohadia, A.K.; Jain, A.; Punjabi, P.B. Fenton and Photo-Fenton Processes. In Advanced Oxidation Processes for Wastewater Treatment: Emerging Green Chemical Technology, 1st ed.; Ameta, S., Ameta, R., Eds.; Academic Press: Cambridge, MA, USA, 2018; pp. 49-87, ISBN 9780128105252.

37. Ghaly, M.Y.; Härtel, G.; Mayer, R.; Haseneder, R. Photochemical oxidation of p -chlorophenol by UV/ $\mathrm{H}_{2} \mathrm{O}_{2}$ and photo-Fenton process. A comparative study. Waste Manag. 2001, 21, 41-47. [CrossRef]

38. Augugliaro, V.; Litter, M.; Palmisano, L.; Soria, J. The combination of heterogeneous photocatalysis with chemical and physical operations: A tool for improving the photoprocess performance. J. Photochem. Photobiol. C Photochem. Rev. 2006, 7, 127-144. [CrossRef]

39. Lee, C.; Keenan, C.R.; Sedlak, D.L. Polyoxometalate-Enhanced Oxidation of Organic Compounds by Nanoparticulate Zero-Valent Iron and Ferrous Ion in the Presence of Oxygen. Environ. Sci. Technol. 2008, 42, 4921-4926. [CrossRef] 
40. Benkelberg, H.; Warneck, P.; Chemie, M. Photodecomposition of Iron (III) Hydroxo and Sulfato Complexes in Aqueous Solution: Wavelength Dependence of $\mathrm{OH}$ and $\mathrm{SO}_{4}$-Quantum Yields. J. Phys. Chem. 1995, 99, 5214-5221. [CrossRef]

41. Kowalik, P. Chemical pretreatment of formaldehyde wastewater by selected Advanced Oxidation Processes (AOPs). Chall. Mod. Technol. 2011, 2, 42-48.

(C) 2020 by the authors. Licensee MDPI, Basel, Switzerland. This article is an open access article distributed under the terms and conditions of the Creative Commons Attribution (CC BY) license (http://creativecommons.org/licenses/by/4.0/). 